\title{
Control of the Development and Prevalence of Antimicrobial Resistance in Bacteria of Food Animal Origin in Japan: A New Approach for Risk Management of Antimicrobial Veterinary Medicinal Products in Japan
}

\author{
Tetsuo Asai,,2 Mototaka Hiki,, Manao Ozawa,, Ryoji Koike,, Kaoru Eguchi,, Michiko Kawanishi," \\ Akemi Kojima, ${ }^{1}$ Yuuko S. Endoh,, Shuichi Hamamoto,' Masato Sakai, and Tatsuro Sekiya ${ }^{3}$
}

\begin{abstract}
Antimicrobial agents are essential for controlling bacterial disease in food-producing animals and contribute to the stable production of safe animal products. The use of antimicrobial agents in these animals affects the emergence and prevalence of antimicrobial resistance in bacteria isolated from animals and animal products. As disease-causing bacteria are often transferred from food-producing animals to humans, the food chain is considered a route of transmission for the resistant bacteria and/or resistance genes. The Food Safety Commission of Japan (FSC) has been assessing the risk posed to human health by the transmission of antimicrobialresistant bacteria from livestock products via the food chain. In addition to the FSC's risk assessments, the Japanese Ministry of Agriculture, Forestry and Fisheries has developed risk-management guidelines to determine feasible risk-management options for the use of antimicrobial veterinary medicinal products during farming practices. This report includes information on risk assessment and novel approaches for risk management of antimicrobial veterinary medicinal products for mitigating the risk of development and prevalence of antimicrobial resistance in bacteria originating from food-producing animals in Japan.
\end{abstract}

\section{Introduction}

A NTIMICROBIAL AGENTS ARE ESSENTIAL for the maintenance of the health and welfare of humans and animals; however, the use of antimicrobials can be linked to the prevalence and emergence of antimicrobial-resistant bacteria (Acar and Rostel, 2001). Resistant bacteria found in foodproducing animals can be transmitted to humans through food chains, possibly reducing the efficacy of antimicrobial therapy in humans (Anonymous, 1969). The impact of antimicrobial-resistant bacteria on human health is a worldwide issue (FAO/OIE/WHO, 2004).

Risk analysis of antimicrobial resistance (Vose et al., 2001) and prudent use of antimicrobials (Anthony et al., 2001) are global principles to aid in the control of antimicrobial resistance in bacteria of animal origin. In Japan, use of antimicrobial veterinary medicinal products (AVMPs) is regulated according to the Pharmaceutical Affairs Law (Law No. 145 of 1960) by The Japanese Ministry of Agriculture, Forestry and Fisheries (JMAFF). Additionally, the Food Safety Commission (FSC), which was established in 2003, has been conducting risk assessments of antimicrobial resistance in food based on the Food Safety Basic Law (Law No. 48 of 2003). Therefore, in 2012, JMAFF adopted guidelines for the risk management of antimicrobial resistance arising from antimicrobial use in food-producing animals (Ministry of Agriculture, Forestry and Fisheries, 2012). This review outlines the regulation of AVMPs as well as procedures for risk analysis of antimicrobial resistance in food-producing animals in Japan.

\section{Regulation of AVMPs: Preliminary Risk Managements}

In Japan, AVMPs are regulated by the Pharmaceutical Affairs Law. The purpose of this law is to control and regulate matters pertaining to drugs, quasidrugs, and medical devices in order to ensure their quality, efficacy, and safety at each stage of development, manufacturing (importing), marketing, retailing, and use.

During the approval process, general and specific data are required for the assessment of AVMPs. These data are evaluated by experts during meetings of the Pharmaceutical

\footnotetext{
${ }^{1}$ National Veterinary Assay Laboratory, Ministry of Agriculture, Forestry and Fisheries, Tokyo, Japan.

${ }^{2}$ Department of Applied Veterinary Science, The United Graduate School of Veterinary Science, Gifu University, Gifu, Japan.

${ }^{3}$ Food Safety and Consumer Affairs Bureau, Ministry of Agriculture, Forestry and Fisheries, Tokyo, Japan.
} 
Affairs and Food Sanitation Council (PASC), conducted by JMAFF. Before being approved, AVMPs are examined by the subcommittee on AVMPs and then by the executive committee of the PASC. The AVMP subcommittee members evaluate the quality, efficacy, and safety of AVMPs. There are specific requirements for obtaining marketing approval for AVMPs in Japan. Because of public and animal health issues, data concerning the antimicrobial spectrum of AVMPS, such as antimicrobial susceptibility tests of recent field isolates of targeted bacteria, indicator bacteria, and foodborne bacteria (Mitsuhashi et al., 1981; CLSI, 2008), as well as resistance acquisition tests (JSAA, 2002), are conducted. For the approval of AVMPs used in food-producing animals, additional data concerning the stability of the antimicrobial substances under natural circumstances has to be evaluated. Moreover, the prohibition and withdrawal periods of AVMPs that are under consideration for use in foodproducing animals are investigated by a separate subcommittee evaluating residue levels for AVMPs. Before the residue levels can be evaluated, the FSC establishes an acceptable daily intake for each ingredient of AVMPs, and the Japanese Ministry of Health, Labor, and Welfare (JMHLW) determines the maximum residue limit (MRL) of AVMPs that can be detected in foods based on the Food Sanitation Act (Law No. 233 of 1947). In addition, the FSC performs qualitative risk assessment of the potential human health risks associated with the use of a particular antimicrobial in food-producing animals after PASC experts have assessed the efficacy and safety of the VMP. The AVMP is approved by the Minister of JMAFF only after it satisfies all requirements.

After approval, AVMPs are further regulated by two distinct systems of postmarketing surveillance in Japan. New AVMPs undergo a re-examination in which field investigation data regarding the efficacy, safety, and public and animal health during a 6-year period are continually evaluated in accordance with Ministerial ordinance No. 33, Series of 2005. Additionally, JMAFF conducts literature reviews on the efficacy, safety, residues, and resistant bacteria for the reevaluation of all approved AVMPs. If the quality, efficacy, or safety of a VMP is suspected to be insufficient as a veterinary and pharmaceutical product, the product must be re-evaluated. The collected and compiled data for re-evaluation of new and currently used VMPS are examined by the PASC subcommittee for re-evaluation of VMPs.

The use and distribution of AVMPs containing clinically important antimicrobials in humans (Food Safety Commission, 2006), such as fluoroquinolones and third- and fourthgeneration cephalosporins, are regulated in Japan. The application for approval of a drug for use in animals is not accepted until the corresponding human-approved drug has completed the re-examination period set by the Minister of JMHLW at the time of approval. In addition, after new drugs are released in this class of AVMPs, data on the quantities sold and the appearance of drug-induced antimicrobial resistance in target and foodborne pathogens are submitted to JMAFF.

The distribution and use of VMPs, including AVMPs, is routinely inspected by the JMAFF. Most approved AVMPs cannot be distributed without a prescription by a licensed veterinarian. Furthermore, the veterinarian cannot prescribe the drug without a diagnosis. The governor of the prefecture conducts qualification examinations for retail sale or de- livery of AVMPs. Veterinary pharmaceutical inspectors appointed by the government in each prefecture are stationed throughout the nation to inspect marketing approval holders, manufacturers, and retailers of VMPs. Additionally, there are label restrictions regarding drug descriptions on "direct containers" and "package inserts" of AVMPs. The package insert must include a description of (1) the prescribed drug; (2) disease and bacterial species for which it is indicated; (3) the route, dose, and period of administration; (4) prohibition/withdrawal periods; (5) precautions for use such as side-effects and safe handling procedures; and (6) in the case of antimicrobial drugs also prescribed for humans (e.g., fluoroquinolones and thirdgeneration cephalosporins), the description must also include an explanation that the drug should not considered a first-line drug.

\section{Risk Assessment of Antimicrobials for the Prevention of the Emergence and Spread of Bacterial Resistance}

The FSC is an entity independent from other riskmanagement organizations such as JMAFF and JMHLW, and conducts risk assessments for foods based on the Food Safety Basic Law (Fig. 1). In December 2003, JMAFF requested the FSC to evaluate 34 AVMPs. The FSC evaluates the potential risk of antimicrobial feed additives and AVMPs. Qualitative risk assessments for foodborne antimicrobial resistance are performed for three types of AVMPs: approved antimicrobials, new antimicrobials at the pre-approval phase (based on a request of the JMAFF), and antimicrobials selected by the FSC.

In September 2004, the FSC developed a guideline for assessing the risk of development of antimicrobial-resistant bacteria due to the use of antimicrobials in livestock production based on the World Organization for Animal Health (OIE) guidelines of antimicrobial resistance, Codex, and U.S. Food and Drug Administration guidelines (Food Safety Commission, 2004). The FSC guideline covers two components: hazard identification and risk assessment. However, these components are described separately, as shown in Figure 2. The components of the FSC and OIE risk assessments are as follows: release assessment, exposure assessment, consequence assessment, and risk estimation. The Codex risk-assessment components are as follows: hazard identification, exposure assessment, hazard characterization, and risk characterization. For risk estimation, the FSC added a ranking system that includes four categories: negligible, low, medium, and high for assessing the importance of antimicrobial resistance in bacteria that affect human health through the food chain (Food Safety Commission, 2004). Based on these four categories, the FSC has thus far conducted risk assessments for antimicrobial-resistant bacteria arising from the use of antimicrobials in food-producing animals for three antimicrobials. Fluoroquinolones used in cattle and swine were estimated as having a medium risk in March 2010 (http://www.fsc.go.jp/fsciis/evaluationDocument/show/kya20071024051); tulathromycin used in swine was estimated as having a medium risk in September 2012 (http://www.fsc.go.jp/fsciis/evaluationDocument/show/kya 20091124004); and pirlimycin used in dairy cows (http:// www.fsc.go.jp/fsciis/evaluationDocument/show/kya200802 12002) was estimated as having a low risk in February 2013. 
The Food Safety Commission

(FSC)

- Risk assessment of foodborne antimicrobial resistance arising from antimicrobial use in food-producing animals

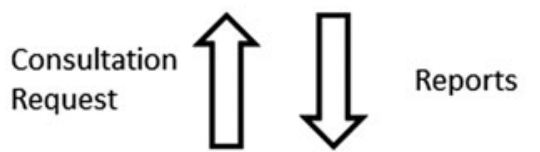

The Japanese Ministry of Agriculture, Forestry and Fisheries (JMAFF)

- Preliminary risk management of AVMPs

- Risk management of AVPMs for foodproducing animals on farms

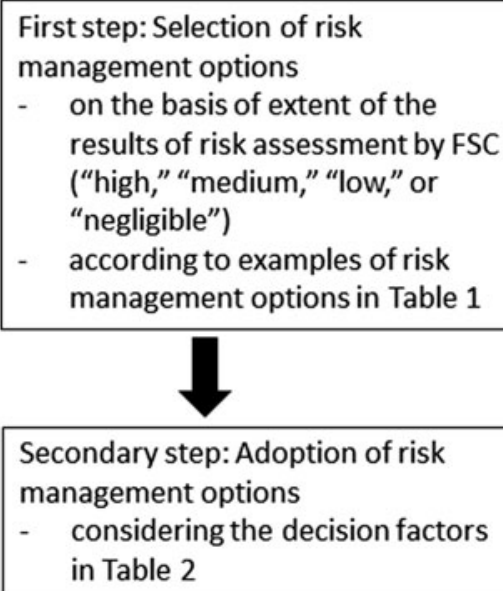

Reports

The Japanese Ministry of Health,
Labor and Welfare
(JMHLW)
- Risk management of foodborne
antimicrobial resistance in the
slaughter of animals and
processing, distribution, and
consumption of animal
products

FIG. 1. Outline of the steps and the organizations involved in risk analysis and management of resistance to antimicrobial veterinary medicines in Japan. AVMPs, antimicrobial veterinary medicinal products.

\section{Guidelines for the Establishment of Risk Management of Veterinary Antimicrobial Products}

Preventing the spread of disease and increasing confidence in food safety are both important issues in animal-related industries. Therefore, to determine and implement riskmanagement options based on FSC risk assessments, management guidelines for reducing the risk of antimicrobial resistance arising from antimicrobial use in food-producing and aquatic animals (but not companion animals) have been established (Ministry of Agriculture Forestry and Fisheries, 2012). These guidelines complement the standard guidelines for riskmanagement adopted by the JMAFF and JMHLW (Ministry of Agriculture Forestry and Fisheries, 2005). The first priority of these management guidelines is to reduce adverse effects on human health. The second priority is the consideration of the significance of AVMPs in veterinary medical treatment.

Risk-management strategies for AVMPs should be established according to the following stepwise approach (Fig. 1). First, risk-management options should be based on the results of an FSC risk-assessment ranking (i.e., high, medium, low, or negligible). For example, a more intensive risk-management program should be established for AVMPs that have a high risk estimation (Table 1). Second, the factors listed in Table 2 should be fully investigated for each target animal and administration route under approval. All AVMPs are approved for treating animal diseases in Japan; therefore, the significance of the use of each AVMP in veterinary medicine should be considered. The severity of the target disease (e.g., organs affected, potential systemic involvement and pathology) should be carefully estimated for each animal species in order to ensure sustainable animal production and to promote animal health and welfare. Additionally, the presence of alternative treatments for the target disease, including different classes of antimicrobials and vaccines, should be considered. In this case, the effects of each candidate antimicrobial on the development and prevalence of resistance due to crossresistance and co-resistance should be assumed as possible. Next, possible harmful consequences are classified as secondary risks entailed in implementing each risk-management option. Use of alternative drugs for treating a target disease of a regulated antimicrobial may result in increase of antimicrobial resistance in foodborne bacteria. For example, use of macrolide antibiotics instead of fluoroquinolones for 


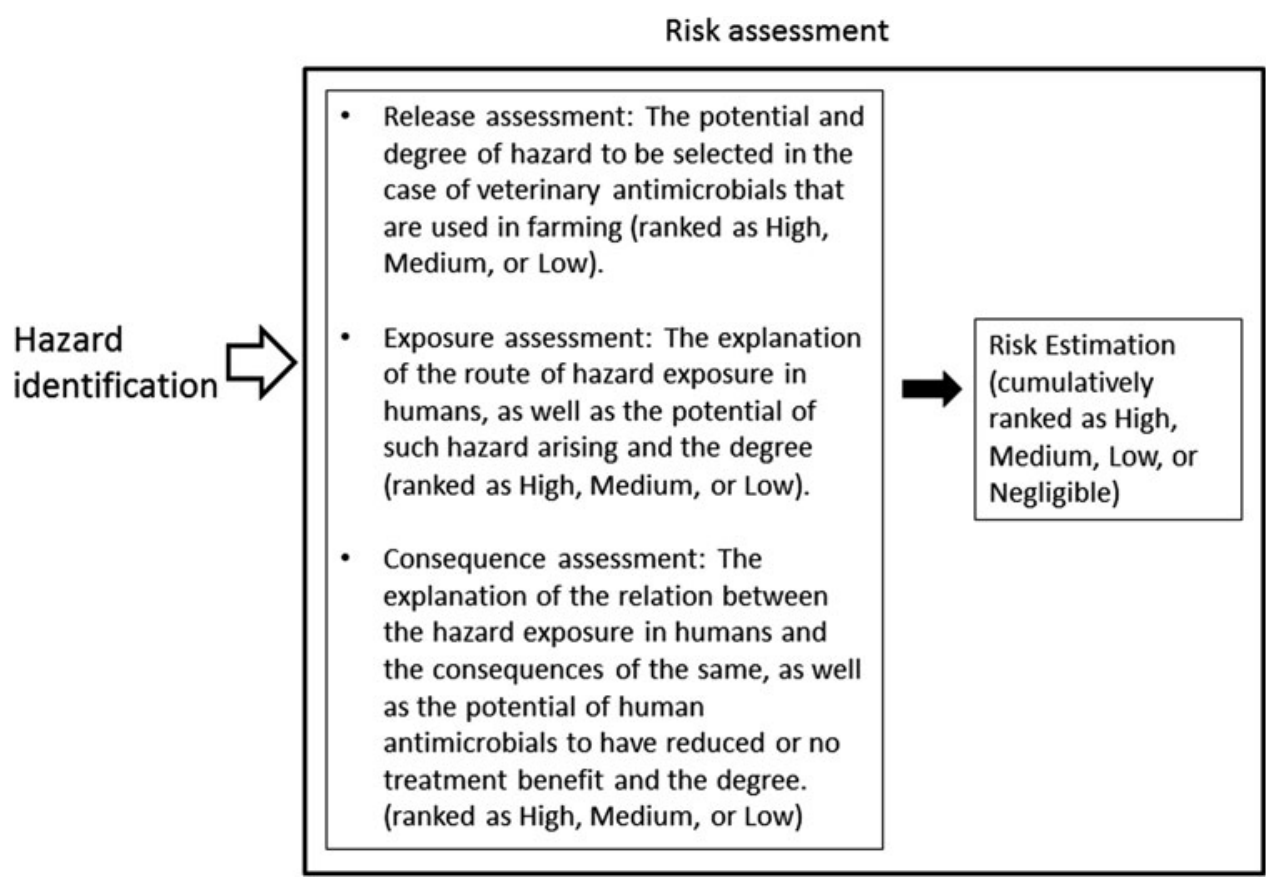

FIG. 2. Flow chart describing the components of the risk-assessment procedure used in Japan to evaluate the risk of antimicrobial resistance development to veterinary products.

Table 1. Selected Examples and Expected Effects of Risk-Management Options for Antimicrobial Drugs Depending on Their Risk-Assessment Result

\begin{tabular}{|c|c|c|}
\hline Assessment result & Examples of risk management options & Expected effects \\
\hline \multirow[t]{2}{*}{ High } & Withdrawal & Distribution of the drug in the country is discontinued. \\
\hline & Temporary ban on use & $\begin{array}{l}\text { Distribution of the drug in the country is discontinued } \\
\text { (temporarily). }\end{array}$ \\
\hline \multirow[t]{5}{*}{ High/ medium } & Withdrawal of the antimicrobial: & \\
\hline & against specific animal species & $\begin{array}{l}\text { When the drug is approved for use in multiple animal } \\
\text { species, it will be banned in some target animals. The use } \\
\text { of the drug for the target animal should be considered for } \\
\text { each administration route of the drug. }\end{array}$ \\
\hline & against target disease/bacteria & $\begin{array}{l}\text { When the drug is approved for multiple target diseases/ } \\
\text { bacteria species, it will be banned in some target diseases/ } \\
\text { bacteria. The use of the drug for the target animal should } \\
\text { be considered for each target disease/bacteria. }\end{array}$ \\
\hline & $\begin{array}{l}\text { Limitation of antimicrobial use near the } \\
\text { time of slaughter }\end{array}$ & $\begin{array}{l}\text { Use volume of the drug is decreased by setting limits on its } \\
\text { use during the final stage of a rearing period; otherwise, a } \\
\text { high amount of the drug would be administered per } \\
\text { animal. This will prevent increases in resistant bacteria } \\
\text { due to selective pressures during the final stage of a } \\
\text { rearing period. }\end{array}$ \\
\hline & $\begin{array}{l}\text { Shortening duration of antimicrobial } \\
\text { administration }\end{array}$ & $\begin{array}{l}\text { A course dose per animal is decreased by shortening a } \\
\text { dosage period of AVMPs based on veterinary diagnosis. }\end{array}$ \\
\hline \multirow[t]{2}{*}{ Medium } & Strict use as secondary line of AVMPs & $\begin{array}{l}\text { The drug is strictly used only when treatment with the } \\
\text { first-line drug is ineffective, as stated on the label of } \\
\text { the specific AVMPs such as new quinolone drugs or } \\
\text { third-generation cephalosporin antibiotics available in Japan. }\end{array}$ \\
\hline & $\begin{array}{l}\text { Intensified monitoring of antimicrobial } \\
\text { resistance }\end{array}$ & $\begin{array}{l}\text { Changes in the resistance of bacteria are detected } \\
\text { immediately by increasing the monitoring frequency and } \\
\text { area. }\end{array}$ \\
\hline Low/ negligible & $\begin{array}{l}\text { Continued monitoring of antimicrobial } \\
\text { resistance }\end{array}$ & \\
\hline
\end{tabular}

AVMPs, antimicrobial veterinary medicinal products. 
Table 2. Basic Components Required to Decide the Risk-Management Options

\begin{tabular}{ll}
\hline Decision factors & \multicolumn{1}{c}{ Comments } \\
\hline $\begin{array}{c}\text { Significance of antimicrobial veterinary } \\
\text { medicinal products in veterinary medicine }\end{array}$ & $\begin{array}{c}\text { Severity (e.g., organs affected, potential systemic involvement, and } \\
\text { pathology) of the target disease } \\
\text { Significance in the clinical settings (e.g., facility, efficacy, and economy) } \\
\text { Availability of alternates including different classes of antimicrobials and } \\
\text { vaccines used for the same purposes } \\
\text { Possible harmful consequences entailed in implementing each } \\
\text { risk-management option } \\
\text { disease }\end{array}$ \\
$\begin{array}{c}\text { Secondary risk } \\
\text { Extent of efficacy imposed by implementing each risk-management option }\end{array}$ \\
$\begin{array}{c}\text { Estimated efficacy of risk-management } \\
\text { option }\end{array}$ & $\begin{array}{c}\text { Feasibility in terms of technical, administrative, and financial issues } \\
\text { involved in implementing each risk-management option } \\
\text { Feasibility of risk-management option } \\
\text { Decision factors depending on antimicrobial characteristics whenever } \\
\text { necessary }\end{array}$ \\
Other concerns &
\end{tabular}

treatment of mycoplasmosis in animals may cause increase in macrolide-resistant Campylobacter. Evaluation of secondary risks plays a key role in balancing public health concerns with animal health and welfare issues. Judging the efficacy and feasibility of risk-management options is also an important element in the successful implementation of risk-management solutions. The last step before adopting any risk-management option should be a final consultation with PASC committee members and communicating the level of risk to the public, if necessary.

\section{Monitoring Antimicrobial-Resistant Bacteria in Food Animals}

Multiple factors appear to be involved in the occurrence and prevalence of antimicrobial-resistant bacteria under selective pressure because of antimicrobial use (Harada and Asai, 2010), and further monitoring and analysis may be required in the veterinary field. The regulatory authority that assesses these risks should evaluate and confirm the decisions regarding risk-management options outlined above. However, there is currently no global monitoring system or coordination regarding the feasibility and efficacy of riskmanagement options. Presently, monitoring of veterinary antimicrobial use and antimicrobial-resistant bacteria on a national level are performed by JMAFF through the Japanese Veterinary Antimicrobial Resistance Monitoring System (JVARM) (Tamura, 2003). The data from this monitoring system can be used for evaluating the performance of the selected risk-management option.

The economic risk for the animal husbandry industry and the potential impact of the risk-management options on animal welfare should also be carefully evaluated after implementing the selected risk-management option. Reduced productivity resulting from the prevalence of disease, reduced growth, and increased mortality can lead to serious economic consequences for animal farms. Although the possibility of harmful consequences is considered when determining risk-management options, the actual economic implications on animal husbandry can be difficult to determine and should therefore be monitored closely.

The JVARM functions as a national monitoring system for evaluating the prevalence of antimicrobial-resistant bacteria in food-producing animals and determines whether their prevalence is associated with antimicrobial use in veterinary medicine (Tamura, 2003). In several countries, national antimicrobial resistance monitoring systems similar to JVARM are in place to gather information throughout the food-production process (DANMAP, 2013; NARMS, 2012). Joint efforts that include both animal and public health organizations are necessary to establish and reinforce these national antimicrobial monitoring systems in order to reduce antimicrobial resistance and increase food safety.

\section{Conclusion}

It is important to determine appropriate risk-management strategies for AVMPs based on scientific assessments and to evaluate their secondary effects on veterinary medicine and animal hygiene. In Japan, AVMPs are regulated during the approval, marketing, distribution, and use stages. Furthermore, risk analyses are carried out by regulatory authorities. Although guidelines considering the feasibility of risk-management options have been established, it is essential to evaluate the efficacy of each riskmanagement option continuously after its implementation and re-evaluate or revise these options if necessary. This issue of risk management for AVMPs should be comprehensively investigated to protect public health, animal health, and food hygiene.

\section{Acknowledgments}

We are grateful to Drs. Tsutomu Sekizaki (The University of Tokyo), Mitsuaki Gohda (Aichi Prefectural Economic Federation of Agricultural Co-operative Associations), Yoshikazu Ishii (Toho University School of Medicine), Satoshi Iwata (Keio University), Munetaka Ooi (Toyoura Veterinary Clinic), and Nobuyuki Yoshiura (Chiba Nosai) for valuable advice regarding the guidelines for the establishment of risk management of veterinary antimicrobial products.

\section{Disclosure Statement}

No competing financial interests exist. 


\section{References}

Acar J, Rostel B. Antimicrobial resistance: An overview. Rev Sci Tech 2001;20:797-810.

Anonymous. Report of the Joint Committee on the Use of Antibiotics in Animal Husbandry and Veterinary Medicine. London: Her Majesty's Stationary Office (HMSO), 1969.

Anthony F, Acar J, Franklin A, Gupta R, Nicholls T, Tamura Y, Thompson S, Threlfall EJ, Vose D, van Vuuren M, White DG. Antimicrobial resistance: Responsible and prudent use of antimicrobial agents in veterinary medicine. Rev Sci Tech 2001;20:829-839.

[CLSI] Clinical and Laboratory Standards Institute. Performance Standards for Antimicrobial Disk and Dilution Susceptibility Tests for Bacteria Isolated from Animals, $3^{\text {rd }}$ ed. CLSI Document M31-A3. Wayne, PA: CLSI, 2008.

[DANMAP] Danish Integrated Antimicrobial Resistance Monitoring and Research Programme. Danish Integrated Antimicrobial Resistance Monitoring and Research Programme (DANMAP) Reports. 2013. Available at: http://www.danmap .org/Downloads.aspx, accessed July 30, 2013.

[FAO/OIE/WHO] Food and Agriculture Organisation/Office International des Epizootias/World Health Organization. Joint FAO/OIE/WHO Expert Workshop on Non-Human Antimicrobial Usage and Antimicrobial Resistance: Scientific Assessment. 2004. Available at: http://whqlibdoc.who.int/hq/ 2004/WHO_CDS_CPE_ZFK_2004.7.pdf, accessed July 30, 2013.

Food Safety Commission. Assessment guideline for the Effect of Food on Human Health Regarding Antimicrobial-Resistant Bacteria Selected by Antimicrobial Use in Food Animals. 2004. Available at: http://www.fsc.go.jp/senmon/ hisiryou/taiseikin_hyoukasisin_english.pdf, accessed July 30, 2013.

Food Safety Commission. Ranking of the Importance of Antimicrobials Against Bacteria Which Affect Human Health Through Food Commodities. 2006. Available at: http://www .fsc.go.jp/senmon/hisiryou/taiseikin_rank_english.pdf, accessed July 30, 2013.

Harada K, Asai T. Role of antimicrobial selective pressure and secondary factors on antimicrobial resistance prevalence in Escherichia coli from food-producing animals in Japan. J Biomed Biotechnol 2010;2010:180682.
[JSAA] Japanese Society of Antimicrobials for Animals. Proc Jpn Soc Antimicrob Anim 2002;24(Suppl):8-14.

Ministry of Agriculture, Forestry and Fisheries. Standard Guideline for Risk Management Adopted by the Ministry of Agriculture, Forestry and Fisheries and Ministry of Health, Labour and Welfare in Japan. 2005. Available at: http:// www.maff.go.jp/j/syouan/seisaku/risk_analysis/sop/pdf/sop_ 241016.pdf, accessed July 30, 2013.

Ministry of Agriculture, Forestry and Fisheries. Guideline for Establishment of Risk Management of Veterinary Antimicrobial Products. 2012. Available at: http://www.maff.go .jp/nval/tyosa_kenkyu/taiseiki/pdf/240411.pdf, accessed July 30, 2013.

Mitsuhashi S, Goto S, Jo K, Kawata T, Kozakai N, Nishino T, Ozawa N, Tanami $\mathrm{H}$. The third revision of standard method for determining minimum inhibitory concentrations of antibiotics against bacteria. Chemotherapy (Japan) 1981;29:76-79. (in Japanese).

[NARMS] National Antimicrobial Resistance Monitoring System. National Antimicrobial Resistance Monitoring System Animal Isolates. 2012. Available at: http://www.ars.usda.gov/ Main/docs.htm?docid=6750, accessed July 30, 2013.

Tamura Y. The Japanese veterinary antimicrobial resistance monitoring system. In: OIE International Standards on Antimicrobial Resistance 2003. OIE Headquarters (ed.). Paris: Office International des Epizooties, 2003, pp. 206-210.

Vose D, Acar J, Anthony F, Franklin A, Gupta R, Nicholls T, Tamura Y, Thompson S, Threlfall EJ, van Vuuren M, White DG, Wegener HC, Costarrica ML. Antimicrobial resistance: Risk analysis methodology for the potential impact on public health of antimicrobial resistant bacteria of animal origin. Rev Sci Tech 2001;20:811-827.

Address correspondence to: Tetsuo Asai, DVM, PhD Department of Applied Veterinary Science The United Graduate School of Veterinary Science Gifu University 1-1 Yanagido Gifu 501-1193, Japan E-mail: tasai@gifu-u.ac.jp 